Research Article

\title{
Synthesis and Characterization of a New Surface-Modified Nanoparticle Using Fluoroalkanoic Acids as a Wettability Alteration Agent
}

\author{
Kenny Ganie $\mathbb{D}^{1},{ }^{1,2}$ Dzeti Farhah Mohshim $\mathbb{D}^{1},{ }^{1}$ Ismail Mohd Saaid $\left(\mathbb{D},{ }^{1}\right.$ \\ Wan Rosli Wan Sulaiman $\mathbb{( D}^{2}$, and Ahmad Kamal Idris $\mathbb{( i )}^{2}$ \\ ${ }^{1}$ Department of Petroleum Engineering, Centre of Enhanced Oil Recovery, Universiti Teknologi PETRONAS, 32610 Seri Iskandar, \\ Perak, Malaysia \\ ${ }^{2}$ Department of Petroleum Engineering, Universiti Teknologi Malaysia, 81310 Johor Bahru, Johor, Malaysia \\ Correspondence should be addressed to Kenny Ganie; kenny_16000607@utp.edu.my
}

Received 28 August 2020; Revised 22 September 2020; Accepted 23 September 2020; Published 9 October 2020

Academic Editor: Marcela Elisabeta Barbinta-Patrascu

Copyright ( 2020 Kenny Ganie et al. This is an open access article distributed under the Creative Commons Attribution License, which permits unrestricted use, distribution, and reproduction in any medium, provided the original work is properly cited.

\begin{abstract}
Previously, condensate banking removal in gas reservoir is mitigated using chemical treatments to alter the wettability of the near-wellbore region. However, this technique performed unsatisfactorily as it reduces the surface free energy and affects the gas relative permeability negatively. Hence, alternative surface-modified nanoparticles using fluorine-based chemicals were developed as wettability alteration agents since fluorine exhibits a high degree of liquid repellency and nanoparticles introduce high surface roughness. The newly synthesized surface-modified nanoparticles were characterized using FTIR, DLS, FESEM, and TGA. FTIR results highlight the characteristic absorption of Si-O-C group at peak 1105 and $1106 \mathrm{~cm}^{-1}$ in both fluoroalkanoic acids, demonstrating that fluorochemical molecules have been successfully coated onto silica nanoparticles. Nanoparticle sizes measured by DLS reported higher value than FESEM due to agglomeration, and the DLS measurement was done in hydrodynamic conditions. TGA analysis reveals decomposition at temperature between 100 and $150^{\circ} \mathrm{C}$, indicating that these surface-modified nanoparticles can be utilized in an environment below $100^{\circ} \mathrm{C}$. Higher decomposition was perceived on PFNA-modified nanoparticles as a thicker coating of PFNA is shrouding the silica nanoparticles compared to PFOA. Implications of the results will path the way for future research direction in using fluorine-based surface-modified nanoparticles as wettability alteration agents.
\end{abstract}

\section{Introduction}

Previous research on wettability alteration only deals with chemical treatment. Fluorochemical or fluorosurfactant is the exact name of the chemical that became the interest of many researchers [1-6] due to its electronegativity and reduction of surface free energy as the fluorine atoms network formed on the surface [7]. Wettability alteration is achieved by adsorption of a surface tension-reducing agent (fluorochemicals) that reduces the surface free energy and causes the repellency of another liquid.

However, chemical treatment is not sufficient to alter the wettability solely. Almost all chemical treatment successfully increases the liquid relative permeability and decreases the irreducible liquid saturation. Nevertheless, this treatment also reduces the gas relative permeability, which is not favourable. Reduction of gas relative permeability will impede the gas well deliverability [3].

Introducing nanoparticles in chemical treatment is not only helping wettability alteration by reducing the surface free energy alone, but also adding another wettability alteration parameter: surface roughness. Increasing surface roughness will increase the wettability alteration ability [8].

Research using nanoparticles as a wettability alteration agent in gas condensate reservoirs only started in 2013 by Mousavi et al. [9]. Several researchers [10] using different types of fluorochemicals and nanoparticles, for example, Mousavi et al. [9] and Sharifzadeh et al. [11], utilized 
TABLE 1: Details of fluoroalkanoic acids used in surface functionalization method.

\begin{tabular}{lccccc}
\hline Chemical & CAS number & Linear formula & Molecular weight & Melting point $\left({ }^{\circ} \mathrm{C}\right)$ & Boiling point $\left({ }^{\circ} \mathrm{C}\right)$ \\
\hline Perfluorooctanoic acid (PFOA) & $335-67-1$ & $\mathrm{CF}_{3}\left(\mathrm{CF}_{2}\right)_{6} \mathrm{COOH}$ & 414.07 & 55 & 189 \\
Perfluorononanoic acid (PFNA) & $375-95-1$ & $\mathrm{CF}_{3}\left(\mathrm{CF}_{2}\right)_{7} \mathrm{COOH}$ & 464.08 & 59 & 218 \\
\hline
\end{tabular}
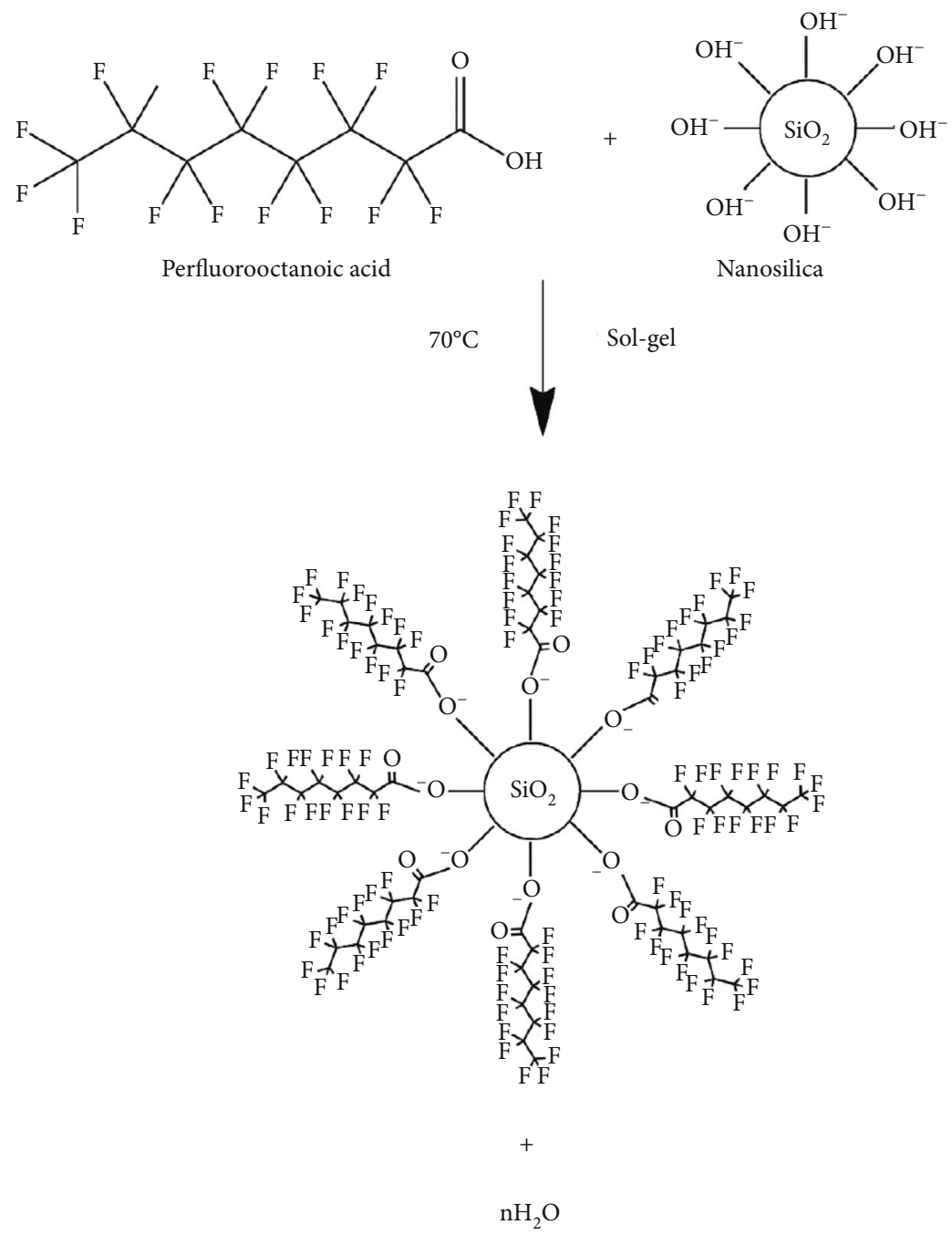

FIGURE 1: Schematic model of the silica nanoparticle formation with perfluorooctanoic acid (PFOA).

fluoroalkylsilane coated on nanosilica through sol-gel preparation. Esmaeilzadeh et al. [12], however, adopted different types of nanoparticles such as titanium oxide, silica, and carbon nanotube coated with fluoropolymer, while Sayed et al. [13] employed silica nanoparticles with fluorinated nonionic polymeric surfactant. Other studies have been applying commercial or proprietary chemicals, such as Franco-Aguirre et al. [14] with anionic commercial surfactant Silnyl ${ }^{\circledR}$ FSJ (SY $-46 \%$ of fluoroaliphatic/hydrocarbon), Jin et al. [15] with $F G-40^{T M}$ fluorosurfactant, and Aminnaji et al. [16] with SurfacePore $M^{T M}$ nanofluid in fluoropolymer. To this day, there has been no research on using fluoroalkanoic acid as the coating agent for silica nanoparticles.
The motivation to use fluoroalkanoic acid as the coating agent comes from Teflon ${ }^{\circledR}$. Fluoroalkanoic acid has been used to manufacture nonstick Teflon ${ }^{\circledR}$-coated cookware. The nonstick surface makes the cookware convenient to use and easy to clean. It also requires little oil or butter for cooking, making it a healthy way to cook and fry food.

The emphasis of this study is on the newly developed fluorinated silica nanoparticles by using fluoroalkanoic acids as the coating agent. This newly developed fluorinated silica nanoparticles will act as a wettability alteration agent. Therefore, the objective of this study is to synthesize and characterize the new surface-modified nanoparticles using fluoroalkanoic acids as wettability alteration agents. 


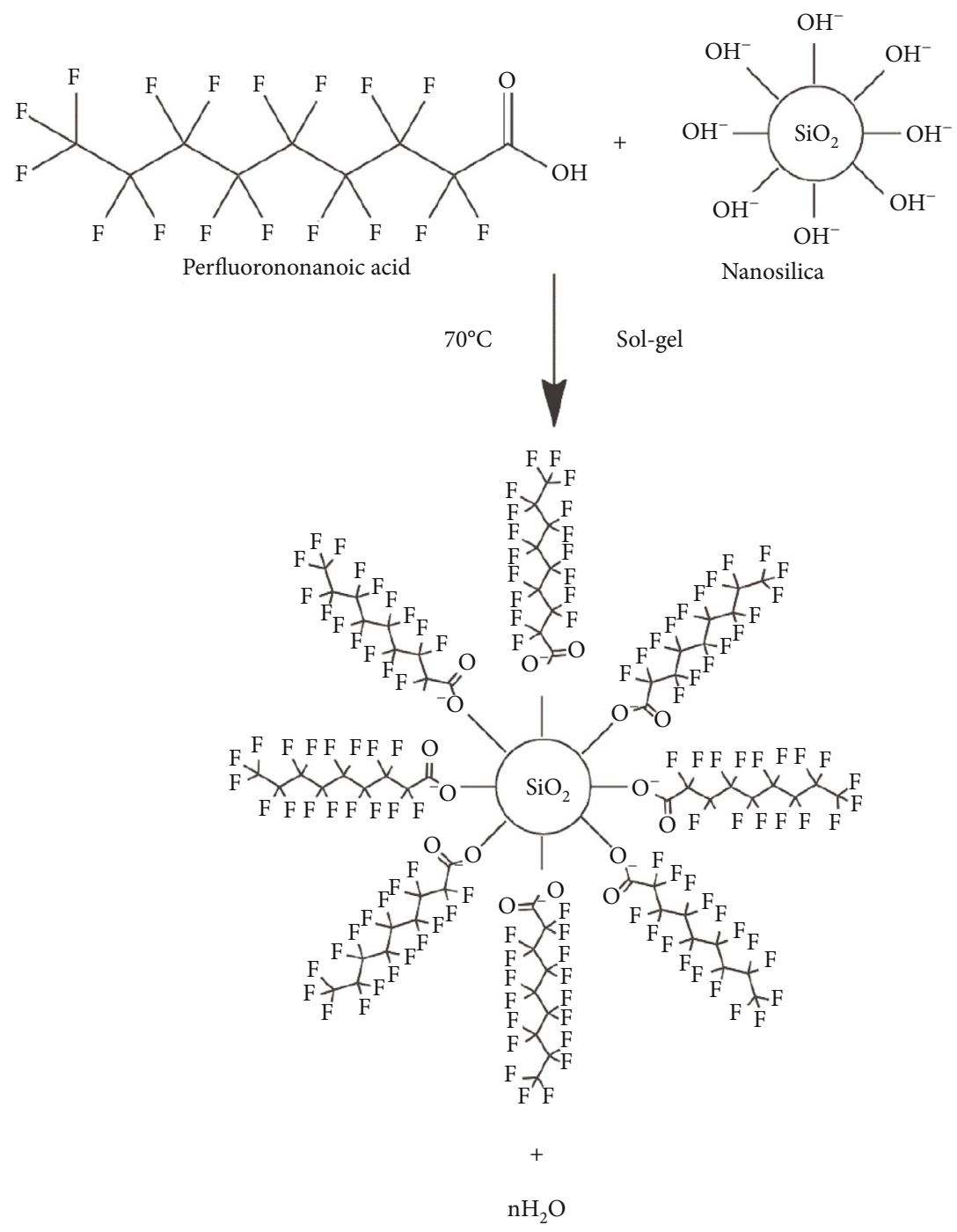

FIGURE 2: Schematic model of the silica nanoparticle formation with perfluorononanoic acid (PFNA).

\section{Materials and Methods}

Perfluorooctanoic acid (PFOA) and perfluorononanoic acid (PFNA) were purchased from Sigma-Aldrich (M) Sdn. Bhd. Details of these chemicals are presented in Table 1. Silicon dioxide $\left(\mathrm{SiO}_{2}\right)$ or silica nanoparticles with hydroxyl functional group $(-\mathrm{OH})$ were supplied by US Research Nanomaterials Inc. The size of nanoparticles is between 15 and $20 \mathrm{~nm}$ with S-type structure (spherical particles). Additionally, ethanol (CAS number: 64-17-5, 95\%) was purchased from HmbG Chemicals.

The synthesis method was conducted using the procedure used in our previous study [17]. Fluorinated nanoparticles were prepared using postsynthesis functionalization method, by dispersing $0.02 \mathrm{~g}$ of $\mathrm{SiO}_{2}$ nanoparticles in $10 \mathrm{~mL}$ ethanol, followed by adding $10 \mathrm{~mL}$ of a mixture containing PFOA $(0.02 \mathrm{~g})$ and ethanol $(10 \mathrm{~mL})$ to the solution at room temperature. Then, the solution was sonicated for 30 minutes with a temperature at $70^{\circ} \mathrm{C}$, above the melting point of PFOA and PFNA. This temperature is selected so that the fluorochemicals (PFOA and PFNA) could coat the nanoparticles easily above its melting point. The experiments above were then repeated using a different type of fluorochemicals, i.e., PFNA. Before characterization, the nanofluid-which is then coated nanoparticles suspended in ethanol-was then sent to the oven at a temperature above ethanol boiling point in order to remove any moisture residues with the nanoparticles. The end product of surface-modified nanoparticles after being dried is in a solid form (powder).

Fourier Transform Infrared Spectroscopy (FTIR) was used to determine the chemical bonds of the neutralwetting alteration agents in this study. FTIR spectrum of the sample was obtained using a Perkin Elmer FTIR Machine, Model Spectrum One to detect the presence of fluorochemicals on the nanoparticle surface. The sample was then mixed with potassium bromide ( $\mathrm{KBr}$ ) pelletsm, and the FTIR device was used in transmission mode in the IR spectra range of $4000-400 \mathrm{~cm}^{-1}$. 


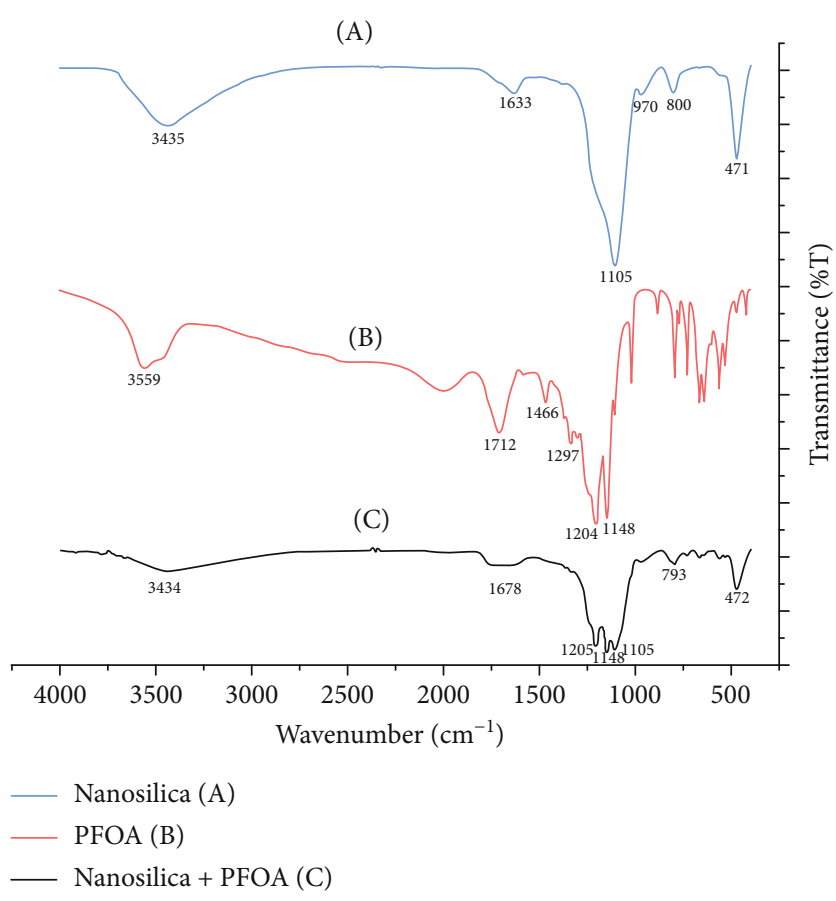

FIGURE 3: FTIR spectra of (a) unmodified nanosilica, (b) perfluorooctanoic acid (PFOA), and (c) PFOA-modified nanosilica.

The size distribution of the nanoparticles in this study was measured using Zetasizer Nano ZSP by Malvern Panalytical. Particle and molecule size is calculated using Dynamic Light Scattering (DLS). DLS tests the diffusion of particles under the Brownian motion and uses the Stokes-Einstein relationship to translate this to scale and size distribution. The Non-Invasive Back Scatter (NIBS) system is implemented to provide the maximum sensitivity at the same time as the largest size and concentration range.

Surface imaging was done using field emission scanning electron microscopy (FESEM). FESEM is an analytical technique used in material science to determine the morphological and topographical data of molecular surface structures. FESEM characterization was done using the VPFESEM model Supra55 VP by Zeiss.

Thermal stability analysis or thermal gravimetric analysis (TGA) was carried out using Simultaneous Thermal Analyzer (STA) 6000 by Perkin Elmer. This test method establishes a procedure for determining the material thermal's stability and its fraction of the volatile component by monitoring the weight change that occurs as a sample is heated at a constant rate. In this study, the nanoparticles were fitted into the TGA sample pan with an initial weight of nominally between 5 and $20 \mathrm{mg}$. The thermal reaction occurred under a nitrogen atmosphere at a rate of $10^{\circ} \mathrm{C} / \mathrm{min}$ from ambient temperature until $900^{\circ} \mathrm{C}$. The decomposition rate will reflect the amount of coating on the nanoparticles and its stability temperatures.

\section{Results and Discussion}

The solution of fluorinated silica nanoparticles of $15-20 \mathrm{~nm}$ size was prepared in the laboratory. Figures 1 and 2 show
(A)

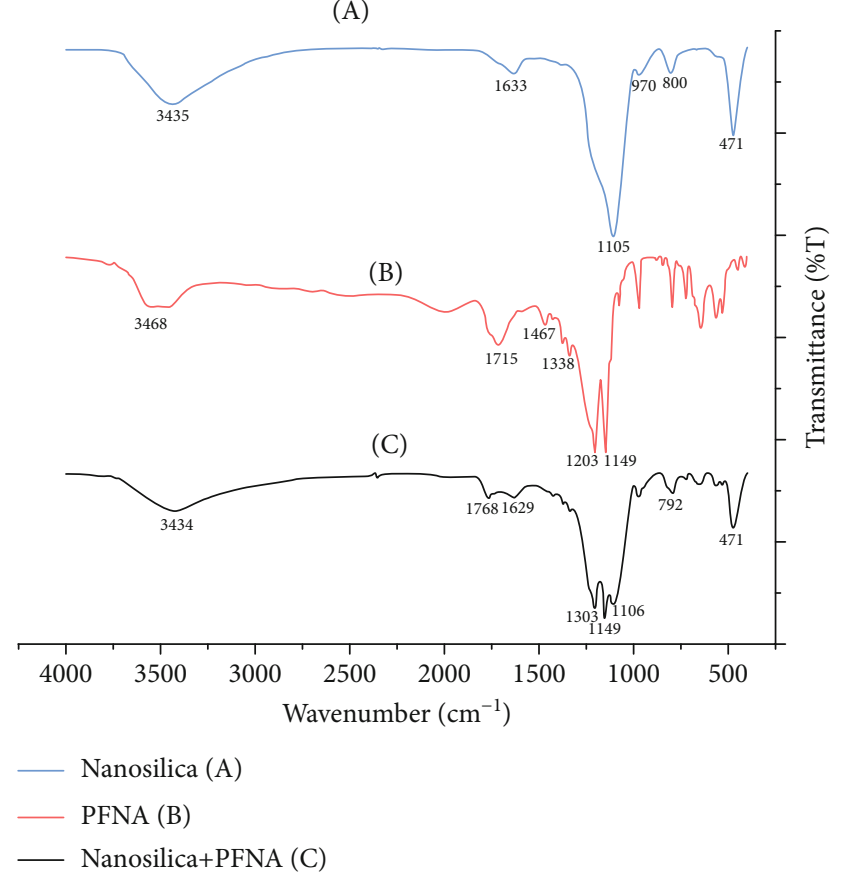

FIgURE 4: FTIR spectra of (a) unmodified nanosilica, (b) perfluorononanoic acid (PFNA), and (c) PFNA-modified nanosilica.

TABLE 2: FTIR spectra of the unmodified nanosilica.

\begin{tabular}{lcc}
\hline $\begin{array}{l}\text { Functional } \\
\text { group }\end{array}$ & $\begin{array}{c}\text { Peak position } \\
\left(\mathrm{cm}^{-1}\right)\end{array}$ & Type of vibration \\
\hline$-\mathrm{OH}$ & $3500-3300$ & $\begin{array}{c}\text { Broad and strong intensity } \\
\text { absorption of -OH stretching } \\
\text { Scissor bending vibration } \\
\text { of O-H bond }\end{array}$ \\
-OH & 1633 & Si-O-Si asymmetric stretching \\
Si-O-Si & 1105 & vibration \\
Si-OH & 970 & $\begin{array}{c}\text { Si-OH asymmetric vibration } \\
\text { Si-O-Si }\end{array}$ \\
Si-O-Si & 800 & Si-O-Si bending vibration \\
\hline
\end{tabular}

the schematic model of the formation of functionalized silica nanoparticles in ethanol solution, with perfluorooctanoic acid (PFOA) and perfluorononanoic acid (PFNA), respectively. From the observation, the dehydration condensation can occur between the hydroxyl group $(-\mathrm{OH})$ of the PFOA and PFNA molecules and the hydroxyl group $(-\mathrm{OH})$ of the nanosilica at temperature $70^{\circ} \mathrm{C}$. Then, the nonpolar end of the C-F bond on the molecule exposes out after the reaction. A substantial number of molecules can react with a single nanoparticle because there are so many hydroxyl groups on the nanoparticles' surface, increasing the adsorption significantly [18]. Therefore, neutral-wetting nanoparticles can be achieved using fluorochemical coating.

Figures 3 and 4 show the FTIR spectrum of unmodified nanosilica, perfluorooctanoic acid (PFOA), perfluorononanoic acid (PFNA), PFOA-modified nanoparticles, and 
TABLE 3: FTIR spectra of perfluorooctanoic acid (PFOA) and perfluorononanoic acid (PFNA).

\begin{tabular}{lccc}
\hline Functional group & Peak position for PFOA $\left(\mathrm{cm}^{-1}\right)$ & Peak position for PFNA $\left(\mathrm{cm}^{-1}\right)$ & Type of vibration \\
\hline O-H & 3559 & 3468 & O-H stretching vibration \\
C=O & 1712 & 1715 & C=O stretching vibration \\
O-H & 1466 & 1467 & O-H bending vibration \\
C-O & 1297 & 1338 & C-O stretching vibration \\
C-F & 1204,1148 & 1203,1149 & C-F stretching vibration \\
\hline
\end{tabular}

TABLE 4: FTIR spectra of PFOA-modified nanoparticles and PFNA-modified nanoparticles.

\begin{tabular}{lccc}
\hline Functional group & $\begin{array}{c}\text { Peak position for PFOA-modified } \\
\text { nanoparticles }\left(\mathrm{cm}^{-1}\right)\end{array}$ & $\begin{array}{c}\text { Peak position for PFNA-modified } \\
\text { nanoparticles }\left(\mathrm{cm}^{-1}\right)\end{array}$ & Type of vibration \\
\hline $\mathrm{C}=\mathrm{O}$ & 1678 & 1768 & C=O stretching vibration \\
$\mathrm{C}-\mathrm{F}$ & 1205,1148 & 1303,1149 & C-F stretching vibration \\
$\mathrm{Si}-\mathrm{O}-\mathrm{C}$ & 1106 & 1106 & Si-O-C stretching vibration \\
$\mathrm{Si}-\mathrm{O}-\mathrm{Si}$ & 793 & 792 & Si-O-Si symmetric vibration \\
$\mathrm{Si}-\mathrm{O}-\mathrm{Si}$ & 472 & 471 & Si-O-Si bending vibration \\
\hline
\end{tabular}

PFNA-modified nanoparticles. The FTIR spectra of the unmodified nanosilica show absorption bands arising from asymmetric stretching vibration of $\mathrm{Si}-\mathrm{O}-\mathrm{Si}$ at $1105 \mathrm{~cm}^{-1}$ and symmetric vibration of $\mathrm{Si}-\mathrm{O}-\mathrm{Si}$ bonds at $800 \mathrm{~cm}^{-1}$. Infrared analysis of the nanosilica shows a peak around $970 \mathrm{~cm}^{-1}$ which is attributed to $\mathrm{Si}-\mathrm{OH}$ bonds, present on the unfunctionalized silica nanoparticles $[19,20]$. The peak at $471 \mathrm{~cm}^{-1}$ is associated with $\mathrm{Si}-\mathrm{O}-\mathrm{Si}$ bonds for the rocking vibration [20-22]. Hydroxyl functional group shows an intense characteristic absorption band between $3300 \mathrm{~cm}^{-1}$ and $3500 \mathrm{~cm}$ ${ }^{1}$ assigned to $\mathrm{O}-\mathrm{H}$ stretching. Also, this band can be crosschecked through the $1633 \mathrm{~cm}^{-1}$ band due to scissor bending vibration of the $\mathrm{O}-\mathrm{H}$ bond [23]. Table 2 shows the summary of IR spectra for the unmodified nanosilica.

Perfluorooctanoic acid (PFOA) and perfluorononanoic acid (PFNA) are from perfluorinated carboxylic acid family. Hence, based on the FTIR, its functional group contains $\mathrm{C}=\mathrm{O}$ stretching bands at $1712 \mathrm{~cm}^{-1}$ and $1715 \mathrm{~cm}^{-1}$; $\mathrm{C}-\mathrm{O}$ stretching bands at $1297 \mathrm{~cm}^{-1}$ and $1338 \mathrm{~cm}^{-1}$; O-H stretching bands at $3559 \mathrm{~cm}^{-1}$ and $3468 \mathrm{~cm}^{-1}$; and $\mathrm{O}-\mathrm{H}$ bending vibration at $1466 \mathrm{~cm}^{-1}$ and $1467 \mathrm{~cm}^{-1}$, for PFOA and PFNA, respectively. C-F stretching vibration is absorbed at $1204 \mathrm{~cm}^{-1}$ and $1148 \mathrm{~cm}^{-1}$ for PFOA and $1203 \mathrm{~cm}^{-1}$ and $1149 \mathrm{~cm}^{-1}$ for PFNA. Table 3 shows the summary of IR spectra for PFOA and PFNA.

In the surface-modified nanoparticles, the absorption peak of -OH group at $3434 \mathrm{~cm}^{-1}$ is broad with weak intensity, indicating that the monomers have reacted slowly. The peaks at $1205 \mathrm{~cm}^{-1}$ and $1148 \mathrm{~cm}^{-1}$ in PFOA-modified nanoparticles and $1303 \mathrm{~cm}^{-1}$ and $1149 \mathrm{~cm}^{-1}$ in PFNA-modified nanoparticles are the characteristic stretching peaks of the $\mathrm{C}-\mathrm{F}$ bonds. The peaks at $1678 \mathrm{~cm}^{-1}$ and $1768 \mathrm{~cm}^{-1}$ in PFOA-modified nanoparticles and PFNA-modified nanoparticles, respectively, are corresponding to the characteristic of absorption $\mathrm{C}=\mathrm{O}$ group. Figures 3(c) and 4(c) show that the characteristic absorption by the Si-O-C group appears at peaks $1105 \mathrm{~cm}^{-1}$ and $1106 \mathrm{~cm}^{-1}$, revealing that fluorochemical molecules have
TABLE 5: DLS of the unmodified and surface-modified silica nanoparticles.

\begin{tabular}{lc}
\hline Sample & Size range $(\mathrm{nm})$ \\
\hline Unmodified nanosilica & $10-15$ \\
PFOA-modified nanosilica & $170-250$ \\
PFNA-modified nanosilica & $210-450$ \\
\hline
\end{tabular}

been successfully coated onto nanosilica particles by the dehydration condensation [18]. The stretching vibration absorption of $\mathrm{Si}-\mathrm{O}-\mathrm{Si}$ at $800 \mathrm{~cm}^{-1}$ in unmodified nanosilica is now shifted to $793 \mathrm{~cm}^{-1}$ in PFOA-modified nanoparticles and $792 \mathrm{~cm}^{-1}$ in PFNA-modified nanoparticles, while bending vibration of $\mathrm{Si}-\mathrm{O}-\mathrm{Si}$ are remained at $471 \mathrm{~cm}^{-1}$ and $472 \mathrm{~cm}^{-1}$, respectively. Table 4 shows the summary of IR spectra for PFOA-modified nanoparticles and PFNAmodified nanoparticles.

Characterization of the functionalized particles by DLS (Table 5) showed the particles to be approximately 100$400 \mathrm{~nm}$ in size and that the uniformity was maintained during the functionalization of the silica nanoparticles. Meanwhile, measurement of nanoparticles using FESEM (Figure 5) showed a lower value, and the size is between 20 and $40 \mathrm{~nm}$. Whilst FESEM measured the primary particle sizes of the nanoparticles, DLS measurements are often done in order to determine the true state of nanoparticles in porous media, especially when it was suspended in nanofluids. If the particles agglomerate, the values obtained from DLS will be larger than FESEM, as DLS measured the average hydrodynamic size of nanoparticles that was dispersed in a solvent.

The surface-modified nanoparticles were further characterized using the TGA method (Table 6). Although nanosilica were oven-dried under vacuum, all samples showed an initial mass loss between 27 and $85^{\circ} \mathrm{C}$, which is assigned to the desorption of physisorbed moisture and residual ethanol 


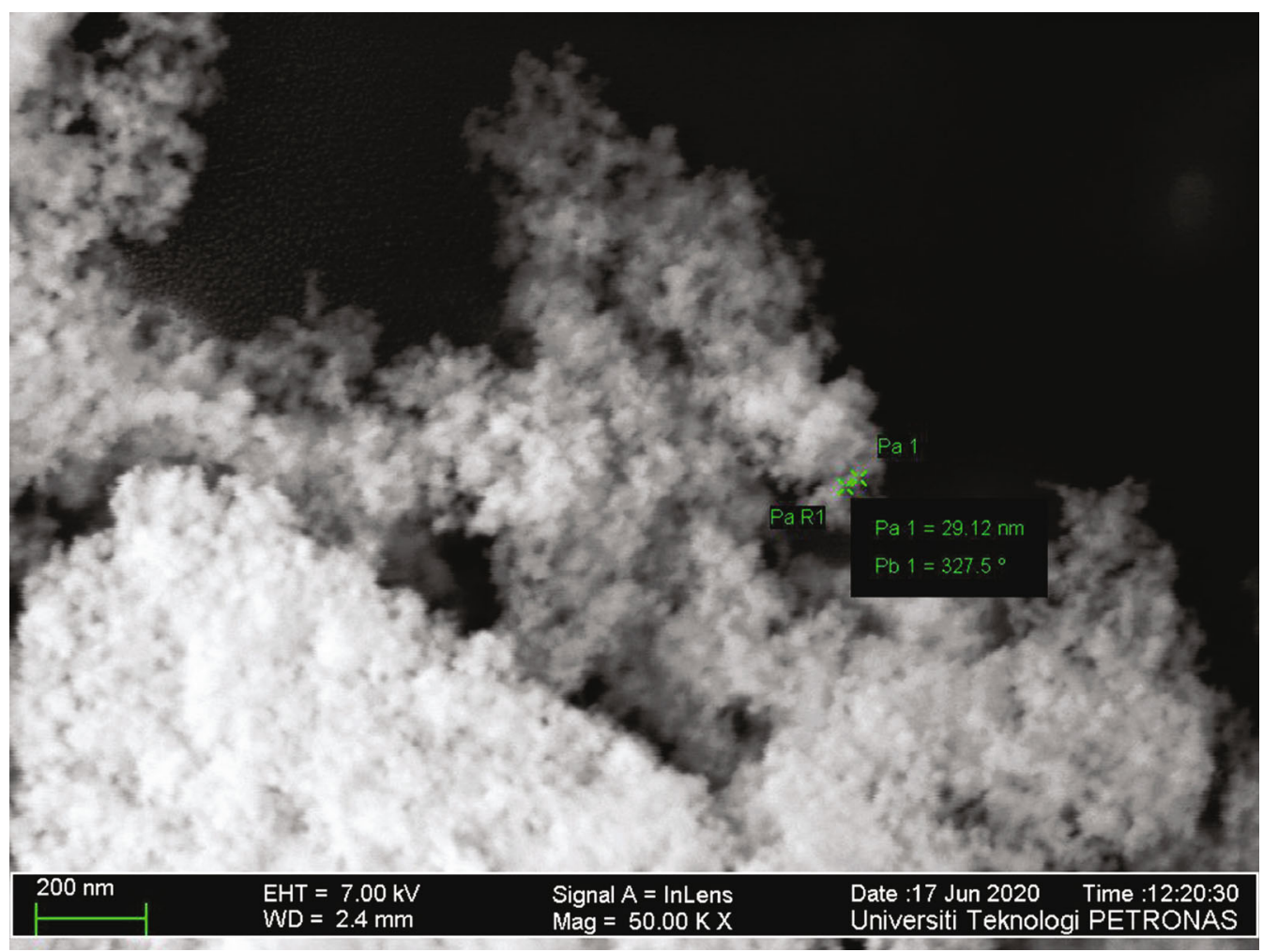

(a)

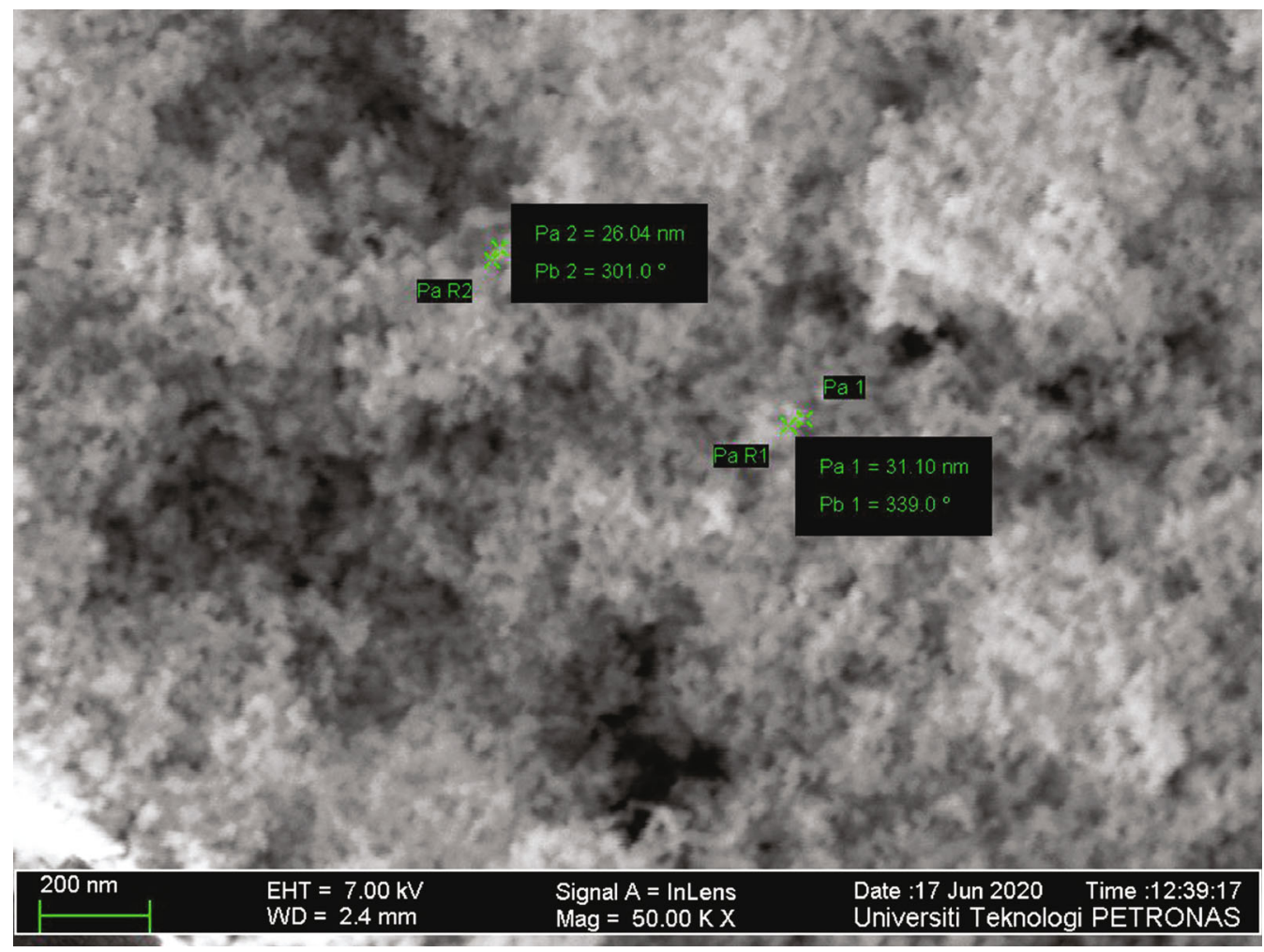

(b)

Figure 5: Continued. 


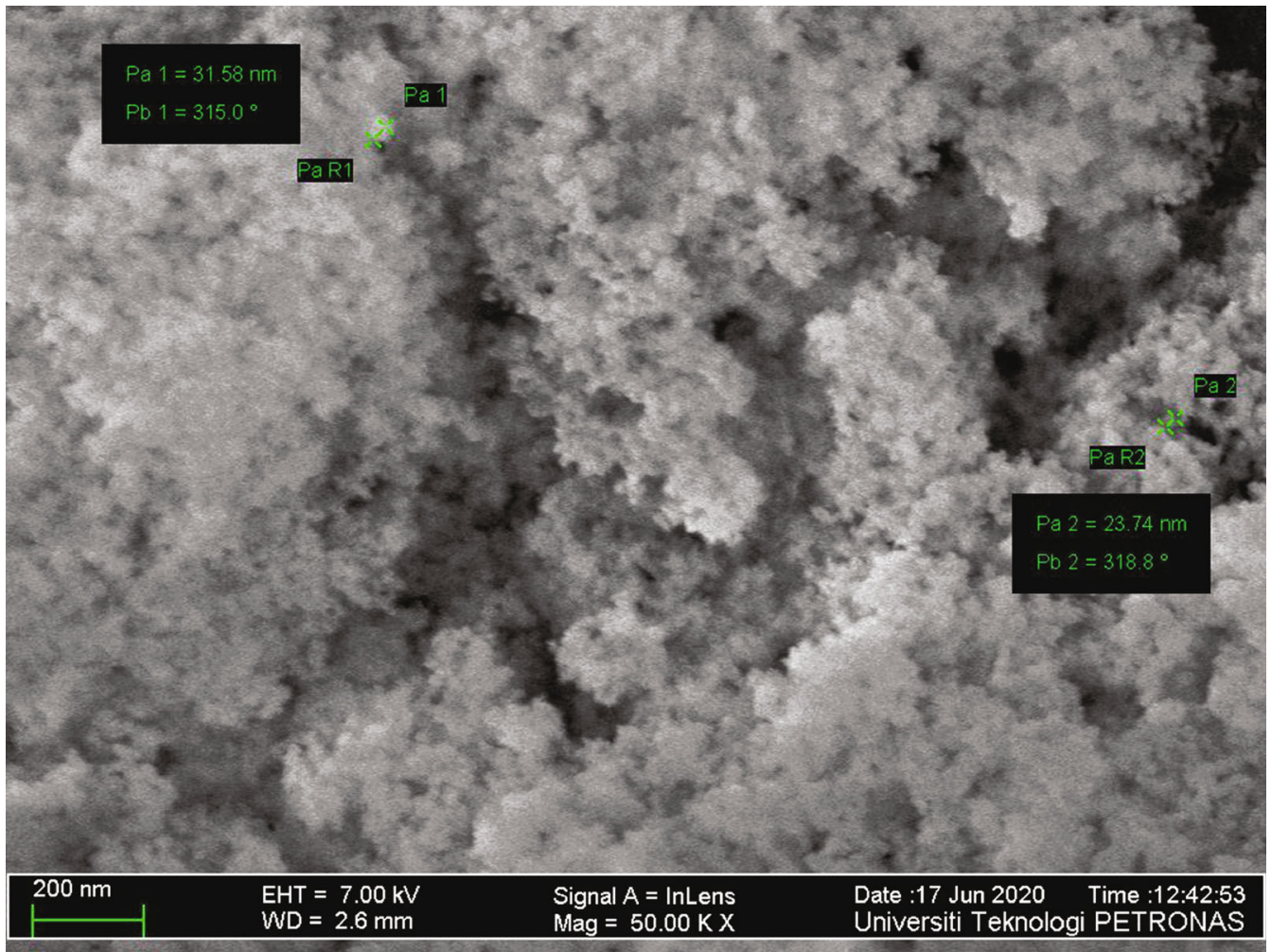

(c)

FIGURE 5: FESEM images of the (a) unmodified nanosilica, (b) PFOA-modified nanosilica, and (c) PFNA-modified nanosilica.

TABLE 6: TGA analyses of the unmodified and surface-modified nanosilica.

\begin{tabular}{lcccc}
\hline Sample & Temperature of 5\% mass loss $\left({ }^{\circ} \mathrm{C}\right)$ & Residual at $100^{\circ} \mathrm{C}(\%)$ & Residual at $150^{\circ} \mathrm{C}(\%)$ & Residual at $900^{\circ} \mathrm{C}(\%)$ \\
\hline Unmodified nanosilica & 600 & 98.0 & 97.8 & 95.0 \\
PFOA-modified nanosilica & 65 & 72.4 & 46.0 & 44.6 \\
PFNA-modified nanosilica & 77 & 85.7 & 42.6 & 34.7 \\
\hline
\end{tabular}

from functionalization of nanoparticles. With the surfacemodified nanoparticles containing only a $\mathrm{SiO}_{2}$ network, they can be dried at elevated temperatures for an extended length of time, ensuring removal of any absorbed moisture and residual ethanol, without compromising any additional organic functionality. No significant weight reduction is observed up until temperature $900^{\circ} \mathrm{C}$ in unmodified nanosilica. Surface-modified silica nanoparticles, however, showed a noticeable weight reduction between the temperatures 100 and $150^{\circ} \mathrm{C}$. PFOA-modified nanoparticles and PFNAmodified nanoparticles both seen $55 \%$ and $65 \%$ of decomposition, respectively. Higher decomposition was perceived on PFNA-modified nanoparticles as a thicker coating of PFNA is shrouding the silica nanoparticles compare to PFOA. Meanwhile, no decomposition is observed in unmodified silica nanoparticles, as no coating was shrouded on the unmodified silica nanoparticles.

These results are in agreement with those obtained by Mousavi et al. [9], Brassard et al. [19], and Jin et al. [18]. One interesting finding is that all the coating agents used in

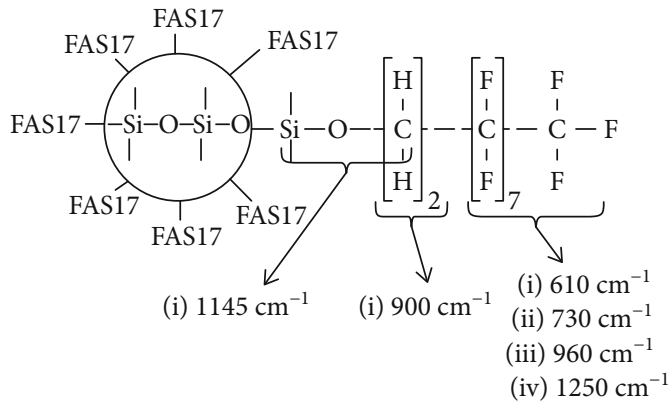

FIgURE 6: The functionalization of silica nanoparticles by FAS17 molecules is shown as well as the vibrational bonds and the corresponding wavenumbers (Brassard et al., 2011).

their study replace the $-\mathrm{OH}$ bond on the nanosilica. For example, Brassard et al. [19] and Mousavi et al. [9] were using fluoroalkylsilane (FAS) as the coating agent. Every $\mathrm{H}$ atom from each $-\mathrm{OH}$ bond around the silica nanoparticles is replaced by a $\mathrm{Si}$ atom of the FAS molecule as presented 


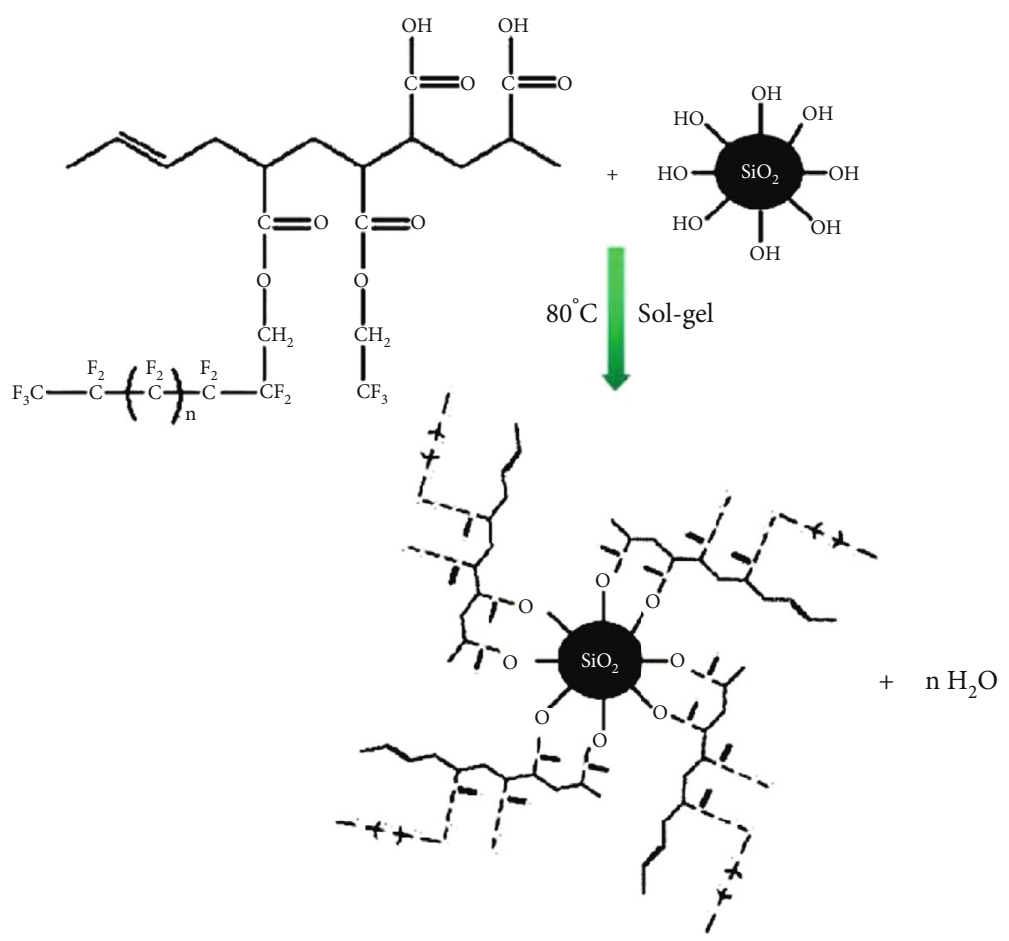

Figure 7: Sketch of nanosilica modification using FG40 fluorosurfactant (Jin et al., 2016).

in Figure 6. The new vibrational bonds of Si-O-C, C-H, and $\mathrm{C}-\mathrm{F}$ are also shown in the same figure.

These similarities are also shared by Jin et al. [18], despite using a different type of coating agent. Although FG40 fluorosurfactant is a proprietary product, the FG40 molecule contains two carboxyl functional groups, as shown in Figure 7. The dehydration and condensation occurred between the -OH group of FG40 and the -OH group of the nanosilica at $80^{\circ} \mathrm{C}$. A substantial number of FG40 molecules can react with a single nanoparticle because there are so many $\mathrm{OH}$ groups on the surface of the nanoparticles.

The combination of these findings provides some support for the conceptual premise that PFOA and PFNA can be used successfully as the coating agent in fluorinatedmodified nanoparticles. An implication of this is the possibility that PFOA-modified nanoparticles and PFNA-modified nanoparticles are acting as wettability alteration agents in removing condensate banking. It is expected that the changes in the chain in nanosilica could improve gas productivity in the gas reservoir.

\section{Conclusions}

In conclusion, fluorinated-modified nanoparticles can be developed using fluoroalkanoic acids such as perfluorooctanoic acid (PFOA) and perfluorononanoic acid (PFNA) as the coating agents. Fluorochemical molecule is successfully coated onto silica nanoparticles, and this is shown in FTIR results. Nanoparticle sizes measured by DLS and FESEM indicate agglomeration of nanoparticles in hydrodynamic environment. TGA analysis showed that these surfacemodified nanoparticles can be utilized in an environment below $100^{\circ} \mathrm{C}$. The evidence from this study suggests that it is possible to synthesize a new surface-modified nanoparticle using fluoroalkanoic acids as a wettability alteration agent, the same coating agent used in nonstick Teflon ${ }^{\circledR}$-coated cookware. Hence, the implications of these results will path the way for future research direction in utilizing surfacemodified nanoparticles using fluoroalkanoic acids as a wettability alteration agent.

\section{Data Availability}

The data used to support the findings of this study are available from the corresponding author upon request.

\section{Disclosure}

Previous work of this paper has been presented in the Science Proceeding Series of the Asia International Multidisciplinary Conference in Johor, Malaysia, April 17-19, 2020.

\section{Conflicts of Interest}

The authors declare that there is no conflict of interest regarding the publication of this paper.

\section{Acknowledgments}

The authors would like to thank the Universiti Teknologi PETRONAS (YUTP Grant 015LC0-227) and the Universiti Teknologi Malaysia (UTM Academic Fellow-SLAM) for providing support and assistance. 


\section{References}

[1] V. Bang, G. Pope, M. M. Sharma, J. Baran, and M. Ahmadi, "A new solution to restore productivity of gas wells with condensate and water blocks," SPE Reservoir Evaluation \& Engineering, vol. 13, no. 2, pp. 323-331, 2010.

[2] K. Li and A. Firoozabadi, "Experimental study of wettability alteration to preferential gas-wetting in porous media and its effects," SPE Reservoir Evaluation \& Engineering, vol. 3, no. 2, pp. 139-149, 2000.

[3] M. H. Noh and A. Firoozabadi, "Wettability alteration in gascondensate reservoirs to mitigate well deliverability loss by water blocking," SPE Reservoir Evaluation \& Engineering, vol. 11, no. 4, pp. 676-685, 2008.

[4] G.-Q. Tang and A. Firoozabadi, "Relative permeability modification in gas/liquid systems through wettability alteration to intermediate gas wetting," SPE Reservoir Evaluation \& Engineering, vol. 5, no. 6, pp. 427-436, 2002.

[5] S. Wu and A. Firoozabadi, "Simultaneous increase in gas and liquid relative permeabilities and reduction of high-velocity coefficient from wettability alteration," Journal of Canadian Petroleum Technology, vol. 50, no. 2, pp. 17-23, 2011.

[6] S. Zhang, G. C. Jiang, L. Wang et al., "Wettability alteration to intermediate gas-wetting in low-permeability gas-condensate reservoirs," Journal of Petroleum Exploration and Production Technology, vol. 4, no. 3, pp. 301-308, 2014.

[7] E. Kissa, Fluorinated Surfactants and Repellents, Marcel Dekker Inc, Wilmington, Delaware, USA, 2nd edition, 2001.

[8] G. Jiang, Gas Wettability of Reservoir Rock Surfaces with Porous Media, Gulf Professional Publishing, 2018.

[9] M. A. Mousavi, S. Hassanajili, and M. R. Rahimpour, "Synthesis of fluorinated nano-silica and its application in wettability alteration near-wellbore region in gas condensate reservoirs," Applied Surface Science, vol. 273, pp. 205-214, 2013.

[10] K. Ganie, A. K. Idris, D. F. Mohshim, W. R. Wan Sulaiman, I. Mohd Saaid, and A. Abdul Malik, "A review on the wettability alteration mechanism in condensate banking removal," Journal of Petroleum Science and Engineering, vol. 183, article 106431, 2019.

[11] S. Sharifzadeh, S. Hassanajili, M. R. Rahimpour, and M. A. Mousavi, "Preparation of the modified limestone possessing higher permeability of gas well based on fluorinated silica: effect of catalyst," Journal of Fluorine Chemistry, vol. 173, pp. 35-46, 2015.

[12] P. Esmaeilzadeh, M. T. Sadeghi, Z. Fakhroueian, A. Bahramian, and R. Norouzbeigi, "Wettability alteration of carbonate rocks from liquid-wetting to ultra gas-wetting using $\mathrm{TiO} 2$, $\mathrm{SiO} 2$ and CNT nanofluids containing fluorochemicals, for enhanced gas recovery," Journal of Natural Gas Science and Engineering, vol. 26, pp. 1294-1305, 2015.

[13] M. Sayed, F. Liang, and H. Ow, "Novel surface modified nanoparticles for mitigation of condensate and water blockage in gas reservoirs," in SPE International Conference and Exhibition on Formation Damage Control, Lafayette, Louisiana, USA, 2018.

[14] M. Franco-Aguirre, R. D. Zabala, S. H. Lopera, C. A. Franco, and F. B. Cortés, "Interaction of anionic surfactantnanoparticles for gas - wettability alteration of sandstone in tight gas-condensate reservoirs," Journal of Natural Gas Science and Engineering, vol. 51, pp. 53-64, 2018.

[15] J. Jin, Y. Wang, T. A. H. Nguyen, A. V. Nguyen, M. Wei, and B. Bai, "The effect of gas-wetting nano-particle on the fluid flowing behavior in porous media," Fuel, vol. 196, pp. 431441, 2017.

[16] M. Aminnaji, H. Fazeli, A. Bahramian, S. Gerami, and H. Ghojavand, "Wettability alteration of reservoir rocks from liquid wetting to gas wetting using nanofluid," Transport in Porous Media, vol. 109, no. 1, pp. 201-216, 2015.

[17] K. Ganie, D. F. Mohshim, I. Mohd Saaid, W. R. Wan Sulaiman, and A. K. Idris, "Development and characterization of surfacemodified-nanoparticles using fluorine-based chemicals," in 4th Asia International Multidisciplinary Conference, vol. 2no. 1, pp. 12-16, Johor, Malaysia, 2020.

[18] J. Jin, Y. Wang, K. Wang, J. Ren, B. Bai, and C. Dai, “The effect of fluorosurfactant-modified nano-silica on the gas-wetting alteration of sandstone in a CH4-liquid-core system," Fuel, vol. 178, pp. 163-171, 2016.

[19] J. D. Brassard, D. K. Sarkar, and J. Perron, "Synthesis of monodisperse fluorinated silica nanoparticles and their superhydrophobic thin films," ACS Applied Materials \& Interfaces, vol. 3, no. 9, pp. 3583-3588, 2011.

[20] J.-D. Brassard, D. K. Sarkar, and J. Perron, "Fluorine based superhydrophobic coatings," Applied Sciences, vol. 2, no. 2, pp. 453-464, 2012.

[21] D. Sarkar, D. Brassard, M. El Khakani, and L. Ouellet, "Dielectric properties of sol-gel derived high-k titanium silicate thin films," Thin Solid Films, vol. 515, no. 11, pp. 4788-4793, 2007.

[22] W. Yang, L. Q. Zhu, Y. C. Chen, H. Ye, and Z. M. Ye, "Surface topography and hydrophobicity of waterborne fluorinated acrylic/silica hybrid coatings," Colloids and Surfaces A: Physicochemical and Engineering Aspects, vol. 484, pp. 62-69, 2015.

[23] A. Beganskiene, V. Sirutkaitis, M. Kurtinaitiene, R. Juskenas, and A. Kareive, "FTIR, TEM and NMR investigations of Stöber silica nanoparticles," Materials Science (Medziagotyra), vol. 10, no. 4, pp. 287-290, 2004. 